Article

\title{
Investigation of Heat Loss from the Finned Housing of the Electric Motor of a Vacuum Pump
}

\author{
Jacek Wernik \\ Institute of Mechanical Engineering, Faculty of Civil Engineering, Mechanics and Petrochemistry, \\ Warsaw University of Technology, Łukasiewicza 17, 09-400 Płock, Poland; jacek.wernik@pw.edu.pl
}

Received: 30 September 2017; Accepted: 22 November 2017; Published: 24 November 2017

\begin{abstract}
Investigation of the heat transfer by conduction and convection through a finned housing of an electric motor rated $373 \mathrm{~W}$ operated in the drive unit of a vacuum pump was carried out. As the speed is changed, so is the velocity of air flow, and consequently, the coefficient of heat transfer across the housing surface is changed too. To predict the values of the average heat transfer coefficient and to determine the heat flow that was dissipated at variable motor speed is a complex task, for which no reliable tools can be found in the literature. Using finite element approximation, the heat transfer was numerically simulated and the temperature distribution on the housing surface was determined. In order to validate the simulation model, an experimental set-up was assembled, including the vacuum pump complete with its driving unit, that is, electrical motor and frequency converter, and FLIR SC7600 thermovision camera. Using the validated simulation model, the heat flux transferred through the housing to the environment and the share of heat dissipation in the power consumed by the vacuum pump drive was determined. The combination of numerical simulation and thermographic measurements is an effective tool.
\end{abstract}

Keywords: numerical simulation; heat conduction; thermography; finned housing

\section{Introduction}

During the operation of an electric motor, heat is dissipated during start-up, speed control, and motor running at constant speed. The conversion of electrical and mechanical energy into heat takes place in both the rotor and stator and in the bearings, resulting in a reduction of the energy efficiency of the machine [1]. Energy converted into heat leads to an increase of the temperature in motor components; their temperature sensivity may lead to emergency situations, such as motor overheating or excessive thermal stresses.

Finned motor housing can be applied in order to prevent emergency situations, such as failure of the rotor, which can occur while the motor is overloaded. The fins provide an increase of heat transfer surface, thus improving the cooling efficiency and enhancing heat dissipation. This also contributes to more uniform temperature distribution in motor parts, and to better working conditions of the motor. Temperature distribution in the finned housing and the associated heat losses can be evaluated by using an approximate analytical solution, which in typical engineering applications is sufficiently accurate under the condition of large temperature differences between the motor housing and the environment [2]. At smaller temperature differences, the determination of heat losses is a complex problem that can be solved by using numerical methods [3], among which, the Finite Element Method (FEM) is widely used. It should be noticed that the Computational Fluid Dynamics (CFD), which includes FEM, is used to determine the temperature distribution in machines [4]. FEM is a method of approximation of partial differential equations, which constitute the mathematical model of the studied object. It should be noted that the results that were obtained with the FEM have an error, which can be neglected while research are properly conducted. Examples of application of the 
FEM in the field of heat exchange can be found in $[5,6]$. Validation of the results can be carried out by using experimental data [7]. In general, after validation, the accuracy of the obtained results can be considered as satisfied when the complexity of the geometrical model is taken into account [8]. Unrealistic assumptions are applied in many studies where steady-state heat transfer in motor is modelled. These assumptions strongly affect the accuracy of the models [9].

The aim of this article is to present a method of evaluating the heat loss by determining the coefficient of convective heat transfer from the housing to the environment, and determining the conduction heat flux that is transferred through the motor housing. Empirical relationships, thermographical measurements, and numerical simulations were applied. Experimental tests were carried out on a single-phase induction electric motor, which is a component of a vacuum pump unit. The studied phenomena included the conduction of heat through the finned motor housing and heat exchange by forced convection between the housing and the environment. An examination of the conditions of heat and energy losses is particularly important in the efforts to reduce energy consumption by machines and devices [10]. Efficient use of energy in production is key to ensuring the healthy functioning of the world economies [11]. This study presents a method for the determination of overall heat losses during the functioning of appliance, which is equipped in finned housing. Which is why it broadens state-of-the-art and make it possible to quickly estimate heat transfer conditions.

\section{Methodology}

Research methodology of investigation of heat loses covers the following three stages: thermographical investigation, empirical determination of the conditions of heat transfer, and numerical simulation.

Figure 1 shows the general appearance of a vacuum pump unit (VALUE, Delhi, India), which included the tested single-phase electric motor whose speed is controlled by a frequency inverter.

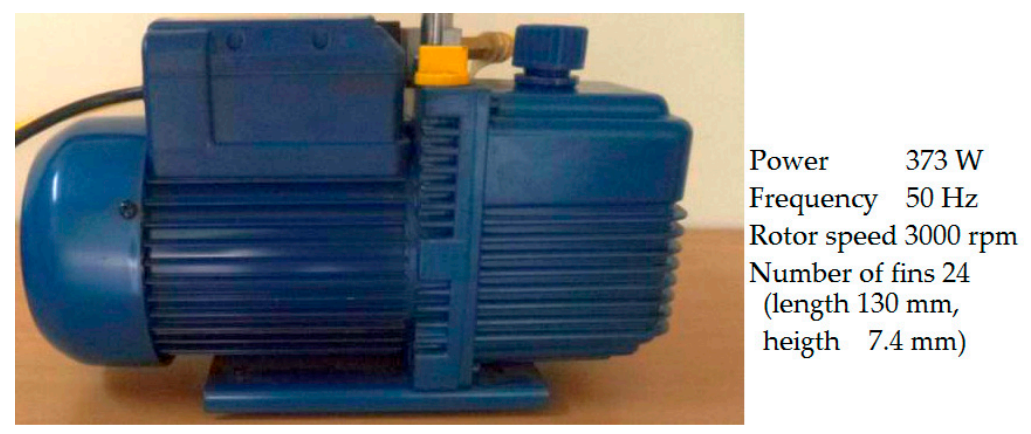

Figure 1. Vacuum pump unit.

The motor housing is made of aluminum. The nominal frequency of the supply current is $50 \mathrm{~Hz}$, which corresponds to the rotational speed of $3000 \mathrm{rpm}$. To the periphery of the motor housing, 24 straight fins are attached with a length of $130 \mathrm{~mm}$ and a height of $7.4 \mathrm{~mm}$. The tested motor is equipped with so-called self-ventilation which involves placing the fan rotor at the end of the motor shaft. The fan rotating at a speed equal to the speed of the motor provides a forced air flow, intensifying the heat transfer outside the housing. The advantage of this solution is its simplicity, while the disadvantage is the dependence of the cooling intensity on the speed of rotation. It can be mentioned that in some studies on self-ventilated electric motors, in the absence of air flow measurements, it was assumed that the flow velocity of air in the channels was equal to $75 \%$ of the peripheral speed of the fan rotor [12]. The results of the heat exchange on electric motor confirmed that the heat is mainly transferred by conduction from the stator/winding assembly to the housing [13].

An experimental setup was built to enable the use of thermography, which is known to be a useful measurement technique for determining heat exchange conditions [14]. Figure 2 shows a scheme of 
the setup, equipped with, among others, a thermovision camera (FLIR, Wilsonville, OR, USA) and instrumentation, which allows for measuring electric power consumed by the motor.

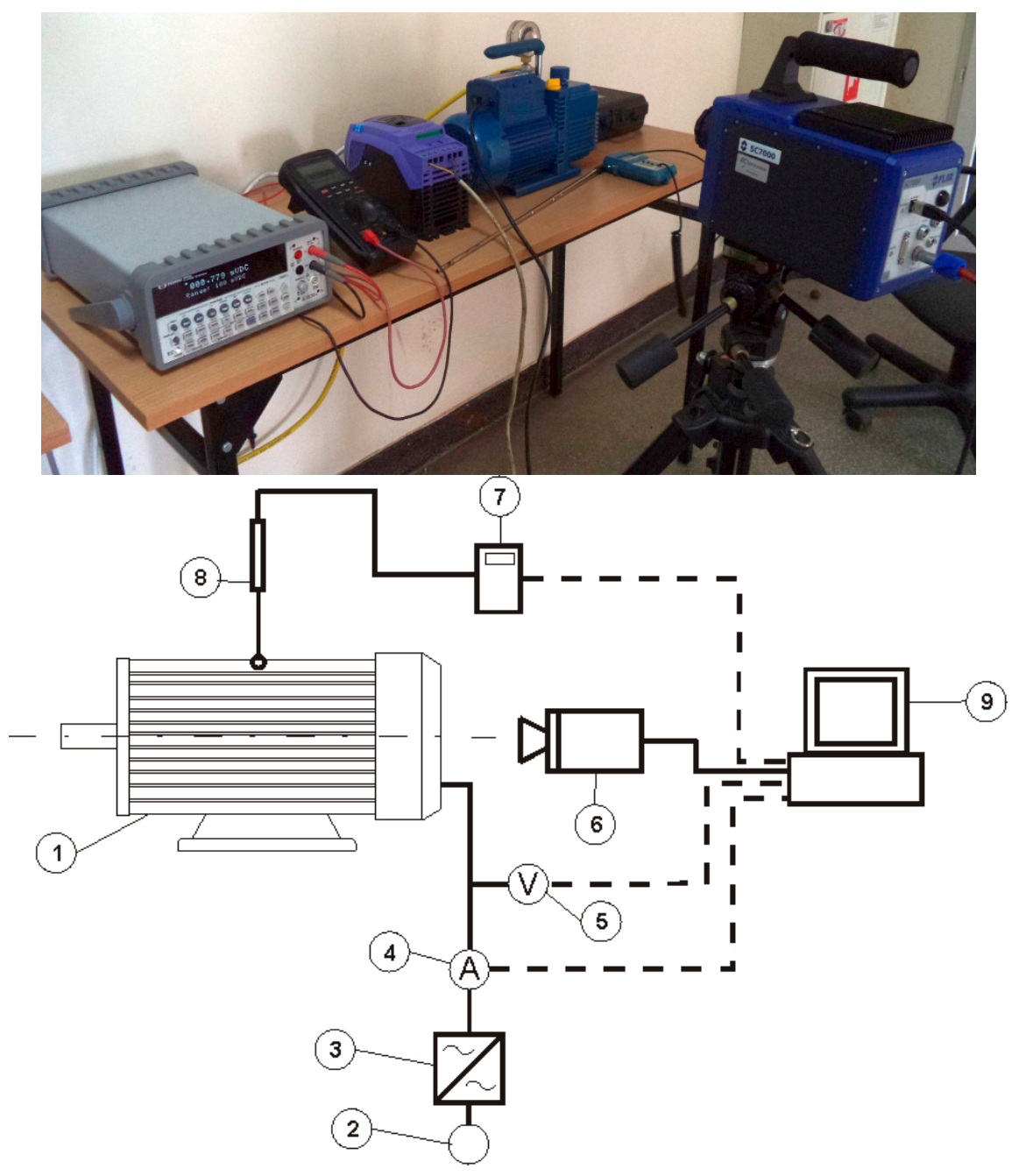

Figure 2. Scheme of the experimental setup. Markings: 1 Vacuum pump unit, 2 AC power, 3 Inverter (Invertek, Welshpool, UK), 4 Ammeter (Protek, Xiamen, China), 5 Voltmeter (Rigol, Beijing, China), 6 Thermovision camera, 7 Anemometer (TSI, St. Pauli, Shoreview, MN, USA), 8 Probe (TSI, St. Pauli, Shoreview, MN, USA), 9 PC (Lenovo, Beijing, China). The dashed line represents manual transfer of information.

Since the spaces between the fins should be considered as semi-open channels, air velocity was measured along the channel axes, at their beginning and end using VelociCheck Air Velocity Meters 8330 (TSI, St. Pauli, Shoreview, MN, USA). Changes in the temperature on the housing surface were observed using FLIR SC7600 thermovision camera for which the parameter NETD (Noise Equivalent Temperature Difference) is $20 \mathrm{mK}$. The signal from the camera was transmitted to a PC, in which the thermal images were obtained for known conditions of heat exchange.

\section{Results and Discussion}

\subsection{Measured Operating Parameters}

The measured values of the air flow velocity and power consumed by the motor, at different values of the frequency of the supply current are shown in Table 1 and Figure 3. 
Table 1. Results of measurements. Bold fonts indicate the nominal current frequency.

\begin{tabular}{ccccc}
\hline Frequency of the Supply Current (Hz) & $\mathbf{4 0}$ & $\mathbf{4 5}$ & $\mathbf{5 0}$ & $\mathbf{5 5}$ \\
\hline $\begin{array}{c}\text { Air flow velocity at the channel } \\
\text { beginning/end (m/s) }\end{array}$ & $2.60 / 1.62$ & $3.80 / 1.88$ & $\mathbf{4 . 6 0 / 2 . 3 0}$ & $4.65 / 2.30$ \\
\hline $\begin{array}{c}\text { Power consumed by the motor (W) } \\
\text { Pown }\end{array}$ & 212 & 243 & $\mathbf{2 4 9}$ & 250 \\
\hline
\end{tabular}

The prediction of the actual decrease of air velocity is a complex function in the case of small power motors. There have to be many factors taken into account including the fan design, shape of fins, cowling shape, and rotational speed. There were not noticeable differences between results of measurements, in particular, channels. The reason is small power of investigated motor.

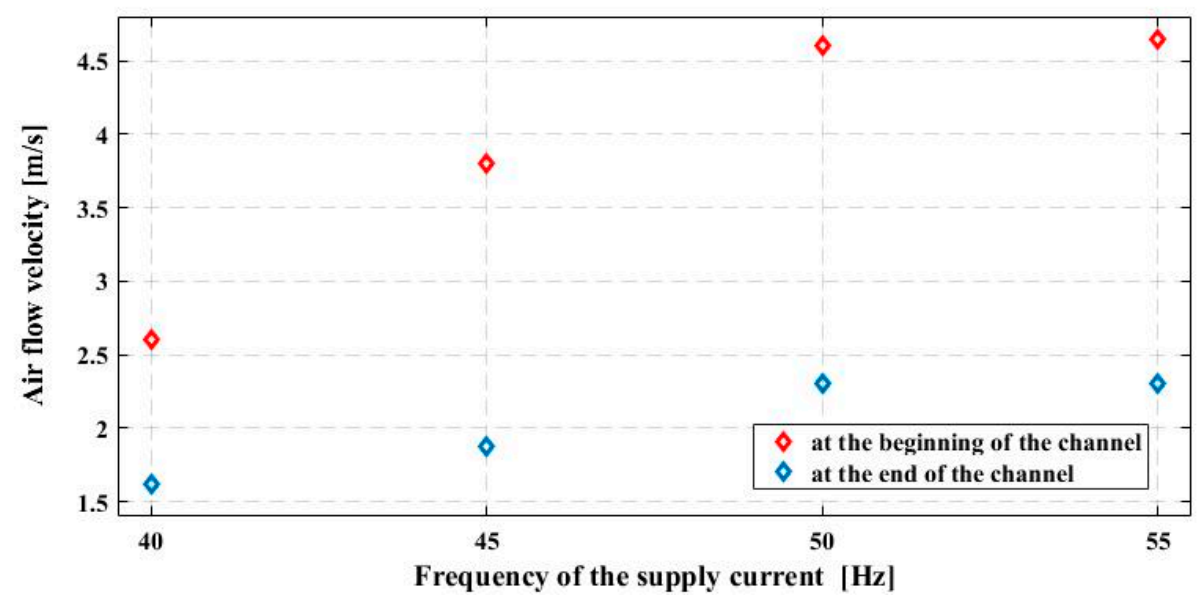

Figure 3. Air flow velocity at the channel beginning/end.

\subsection{Thermographical Investigation}

The emissivity of the paint-coated outer surface of the motor housing was determined experimentally by comparative measurement employing a reference surface with a constant, known emissivity. As a reference that meets the above conditions the surface of duct tape Scotch Super 33+ (3M Electrical Product Division, Tonawanda, NY, USA) was assumed. In the literature, its emissivity is reported as 0.96 [15]. This value has been confirmed by the author' own measurements. The comparative measurement resulted in estimating the emissivity of the housing surface at 0.96 . Using the thermovision camera at an ambient temperature of $295 \mathrm{~K}$, thermal images were recorded to determine the actual temperature distribution on the surface of the housing. The set of temperature values that were constituting the thermal image was subsequently used to determine the average temperature on the housing surface. Averaged temperature values for the four values of the current frequency were then used to determine the corresponding values of the convective heat transfer coefficient. The average values of temperature are presented in Table 2.

Table 2. Measured temperature values. Bold fonts indicate the nominal current frequency.

\begin{tabular}{lcccc}
\hline Frequency of the Supply Current (Hz) & $\mathbf{4 0}$ & $\mathbf{4 5}$ & $\mathbf{5 0}$ & $\mathbf{5 5}$ \\
\hline Average temperature of the housing (K) & 314.05 & 311.43 & $\mathbf{3 0 6 . 1 0}$ & 315.42 \\
\hline
\end{tabular}

Figure 4 shows the thermogram of housing surface obtained for the nominal current frequency of $50 \mathrm{~Hz}$. Lines from 1 to 6 indicates the points from which temperature data were collected for the analysis of temperature distribution. Converted to a graph, as shown in Figure 5, these data illustrate the temperature changes in a direction transverse to the axis of the motor, including the temperature 
variations along the height of the fins (lines 1-3). The peaks visible in the graph at a length of $90 \mathrm{~mm}$ correspond to the position of the tension screw that stabilizes the fan cover.

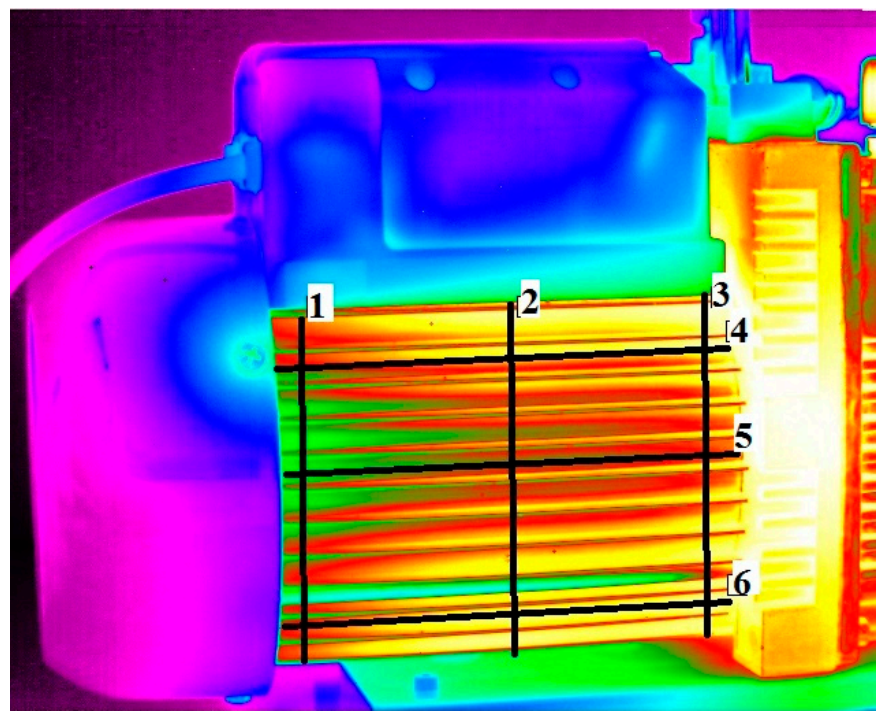

Figure 4. Thermogram of the housing. (Lines: 1 to 6 shows the location of points from which measured temperature values were taken to generate the diagram of temperature distribution shown in Figures 5 and 6 .

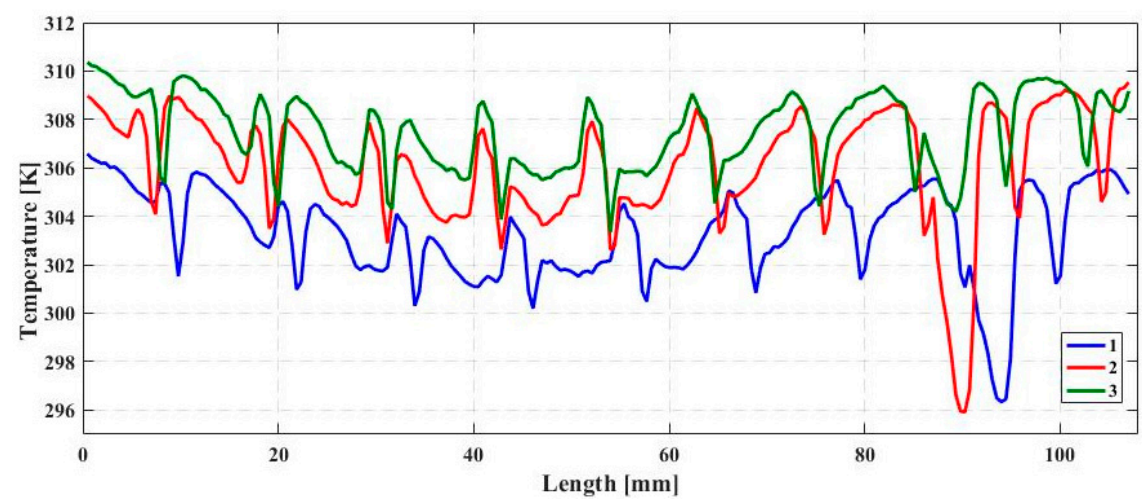

Figure 5. Temperature distributions along the selected lines (see Figure 4).

There are temperature changes shown in a longitudinal direction to the axis of the motor (lines 4-6) in Figure 6.

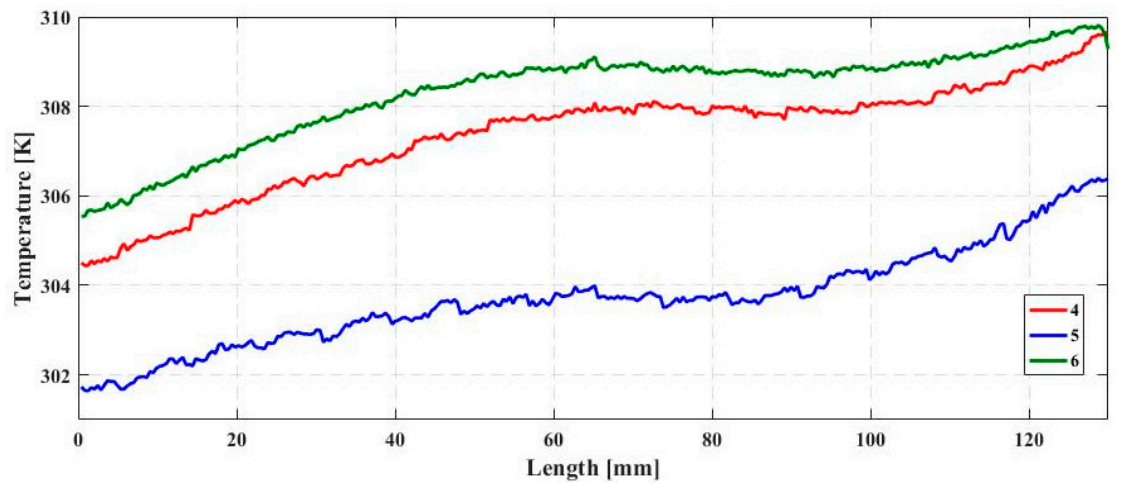

Figure 6. Temperature distributions along the selected lines (see Figure 4). 


\subsection{Convective Heat Transfer Coefficients}

The values of convective heat transfer coefficients can be calculated from empirical relationships. It is commonly assumed that the fan rotor mounted on the motor shaft causes turbulent air flow along the housing. The location of the fins on the housing implies that semi-open longitudinal channels are formed for the flow of air blown by the fan. As the experimental setup made it possible to measure the flow velocity, the values of convective heat transfer coefficients were determined using the formula presented in [16]:

$$
h=\frac{\rho C_{p} D v}{4 L}\left(1-\mathrm{e}^{-n}\right)
$$

where parameter $n$ is calculated from the formula:

$$
n=0.1448 \frac{L^{0.946}}{D^{1.16}}\left(\frac{k_{a}}{\rho C_{p} v}\right)^{0.214}
$$

and $\rho$-material density, $C_{p}$-heat capacity at constant pressure, $k_{a}$-thermal conductivity of air, $v$-inlet air velocity in the fin channels, $L$-axial length of cooling fins, $D$-hydraulic diameter (four times the channel area divided by the channel perimeter, including the open side).

The calculated convection coefficient should be multiplied by the so-called turbulence factor that is typically equal to 1.8. Figure 7 shows the values of so determined convective heat transfer coefficients.

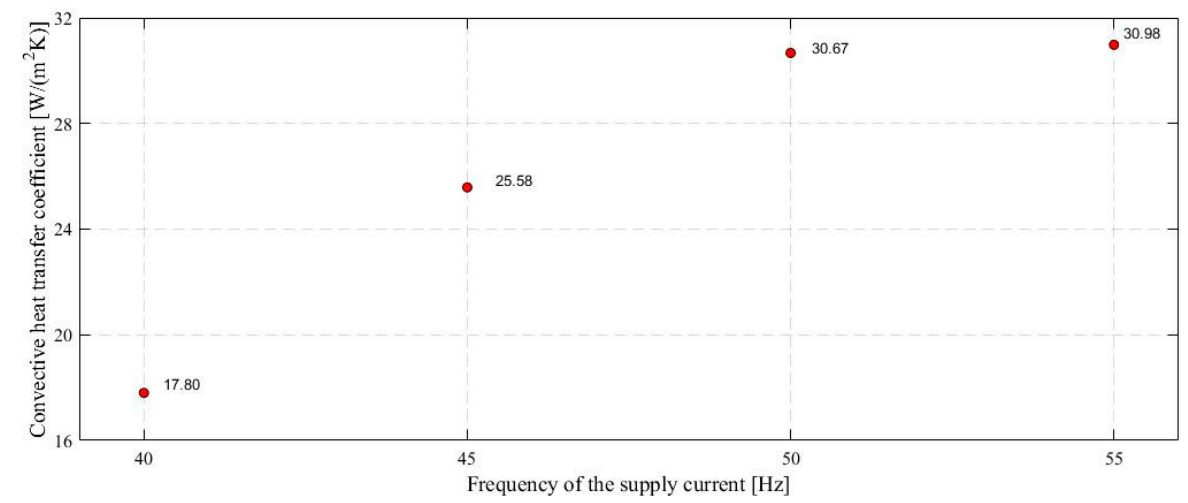

Figure 7. Values of the convective heat transfer coefficients.

\subsection{Numerical Simulations}

In order to determine the heat flux that was dissipated from the motor housing, an approach was developed employing the comparison of the results of measurements that were performed in the experimental setup with these of FEM-based computer simulations. As a simulation tool, COMSOL Multiphysics (3.5, COMSOL AB., Burlington, MA, USA) package was applied. This package was validated in the field of heat transfer by Pryor [17]. The following mathematical model of the steady-state heat transfer with convection and conduction is used in COMSOL:

$$
\nabla(-\mathrm{k} \nabla \mathrm{T})=Q-\rho C_{p} v \nabla \mathrm{T}
$$

where $T$-temperature, $k$-thermal conductivity, $Q$ - heat generation per unit volume.

The geometrical form of the finned motor housing was numerically modelled in two-dimensional (2-D) using CAD tools of COMSOL Multiphysics package. Regarding the boundary conditions, the following assumptions were adopted:

- thermal conductivity for aluminum: $180 \mathrm{~W} /(\mathrm{mK})$,

- ambient temperature: $295 \mathrm{~K}$, 
- external housing surface exposed to the ambient air is cooled by forced convection described by the expression:

$$
-k \frac{\partial \mathrm{T}}{\partial \mathrm{n}}=h\left(T-\mathrm{T}_{\mathrm{f}}\right)
$$

where, $n$ - unit vector normal to the studied surface, $T_{f}$-ambient temperature.

The interaction between air and external surface housing was modeled by convective heat transfer taken into account. The value of coefficient was calculates by using Equation (1). The values for the coefficient for each considered case are shown in Figure 7.

Heat losses are function of heat flux transferred onto the inner surface of motor housing. The flux was one of the boundary conditions in numerical model. The value of heat flux was being changed so that the results of average outside temperature of housing were as close as possible to the results of thermographical measurement. A series of simulations were performed for the various current frequencies. The distribution of housing temperature in cross-section for the heat value of $26.95 \mathrm{~W}$ is shown in Figure 8. It is the case of current frequency of $50 \mathrm{~Hz}$ and mean value of housing surface temperature of $306.10 \mathrm{~K}$ (equal to the mean value obtained from the thermographic studies).

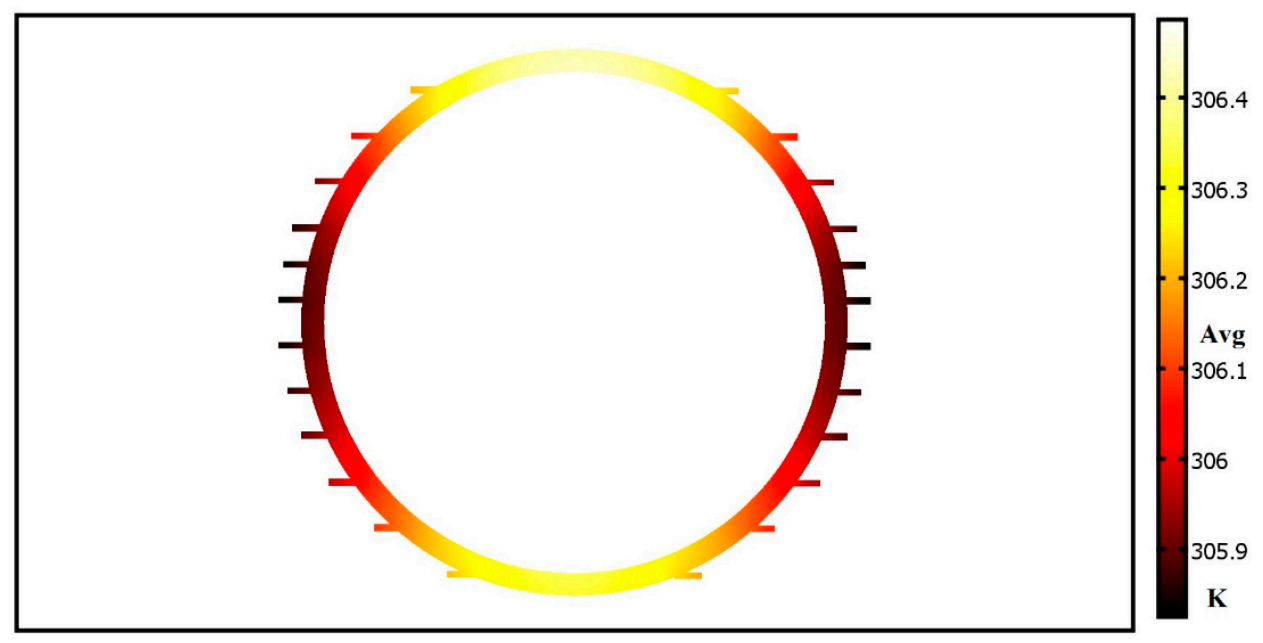

Figure 8. Temperature distribution in cross-section of the housing.

The validation of the numerical results was carried out by comparing the obtained values $T_{\text {simul }}$ with temperature measurements $T_{\text {measured }}$ in the corresponding conditions. A numerical model is considered, as well-validated if a relative difference of aforementioned results is less than $10 \%[18,19]$. The relative difference is calculated as:

$$
\varepsilon=\frac{\left|\Delta T_{\text {measured }}-\Delta T_{\text {simul }}\right|}{\Delta T_{\text {measured }}} \times 100 \%
$$

Average temperature values simulated/measured at fin base and fin head are given in Table 3 , where the value of relative difference $\varepsilon \%$ is also shown.

Table 3. Numerical results and their comparisons with experimental results.

\begin{tabular}{ccccc}
\hline Frequency of the Supply Current (Hz) & $\mathbf{4 0}$ & $\mathbf{4 5}$ & $\mathbf{5 0}$ & $\mathbf{5 5}$ \\
\hline base/head of fin, $T_{\text {measured }}(\mathrm{K})$ & $314.60 / 313.20$ & $311.80 / 310.82$ & $306.67 / 305.90$ & $315.04 / 313.99$ \\
base/head of fin, $T_{\text {simul }}(\mathrm{K})$ & $314.57 / 313.28$ & $311.81 / 310.91$ & $306.64 / 305.92$ & $315.06 / 313.91$ \\
$\varepsilon \%$ & 9.28 & 8.16 & 6.49 & 9.52 \\
\hline
\end{tabular}

The results clearly demonstrate that the relative difference is within a $10 \%$ margin. 


\section{Conclusions}

Heat dissipation from the electric motor used as component of a vacuum-pump unit was studied. Concomitant use of experimental tests, including thermal imaging and numerical simulations enabled the precise determination of the resulting power loss.

The study was conducted in three stages. An experimental set-up was built to measure the power that was consumed by the motor and the speed of cooling air flowing along the channels between the fins. Thermal measurements were performed on the actual motor housing for a variety of working conditions, and thermographic images were recorded to determine the temperature distribution on the housing surface. Then, numerical simulations were carried out using COMSOL Multiphysics software package.

The determination of convective heat transfer coefficients was of particular importance in defining the appropriate boundary conditions needed for the simulations. By combining numerical simulation with the experimental verification of calculation results, for nominal operating conditions, it was found out that $10.82 \%$ of the power supplied to the motor is lost by heat dissipation.

The combination of thermographic imaging and numerical simulation proved to be an effective tool that can be applied to rationalizing design of electrical equipment, in which finned housing is used. In the studied case, the obtained results allow for further research on the selection of types and dimensions of fins attached to the motor housing.

The proposed investigation of steady-state heat transfer by using numerical and thermographical methods from the housing of the motor provides accurate results in comparison with ones that are based on analytical modelling only.

Conflicts of Interest: The author declare no conflict of interest.

\section{References}

1. Da Costa Bortoni, E. Are my motors oversized? Energy Convers. Manag. 2009, 50, 2282-2287. [CrossRef]

2. Aziz, A.; Bouaziz, M.N. A least squares method for a longitudinal fin with temperature dependent internal heat generation and thermal conductivity. Energy Convers. Manag. 2011, 52, 2876-2882. [CrossRef]

3. Xie, Y.; Wang, Y. 3D temperature field analysis of the induction motors with broken bar fault. Appl. Therm. Eng. 2014, 66, 25-34. [CrossRef]

4. Pyrhönen, J.; Lindh, P.; Polikarpova, M.; Kurvinen, E.; Naumanen, V. Heat-transfer improvements in an axial-flux permanent-magnet synchronous machine. Appl. Therm. Eng. 2015, 76, 245-251. [CrossRef]

5. Liu, G.R.; Quek, S.S. The Finite Element Method; Butterworth-Heinemann: Oxford, UK, 2014. [CrossRef]

6. Baskharone, E.A. The Finite Element Method with Heat Transfer and Fluid Mechanics Applications; Cambridge University Press: New York, NY, USA, 2014.

7. Moradnia, P.; Golubev, M.; Chernoray, V.; Nilsson, H. Flow of cooling air in an electric generator model-An experimental and numerical study. Appl. Energy 2014, 114, 644-653. [CrossRef]

8. Tosetti, M.; Maggiore, P.; Cavagnino, A.; Vaschetto, S. Conjugate heat transfer analysis of integrated brushless generators for more electric engines. IEEE Trans. Ind. Appl. 2014, 50, 2467-2475. [CrossRef]

9. Klimenta, D.; Hannukainen, A. Novel approach to analytical modelling of steady-state heat transfer from the exterior of TEFC induction motors. Therm. Sci. 2016, 21, 1529-1542. [CrossRef]

10. Krajačić, G.; Duić, N.; Rosen, M.A. Sustainable development of energy, water and environment systems. Energy Convers. Manag. 2015, 125, 1-14. [CrossRef]

11. Yong, J.Y.; Klemeš, J.J.; Varbanov, P.S.; Huisingh, D. Cleaner energy for cleaner production: Modelling, simulation, optimisation and waste management. J. Clean. Prod. 2016, 111, 1-16. [CrossRef]

12. Romo, J.L.; Adrián, M.B. Prediction of internal temperature in three-phase induction motors with electronic speed control. Electr. Power Syst. Res. 1998, 45, 91-99. [CrossRef]

13. Wrobel, R.; Vainel, G.; Copeland, C.; Duda, T.; Staton, D.; Mellor, P.H. Investigation of Mechanical Loss Components and Heat Transfer in an Axial-Flux PM Machine. IEEE Trans. Ind. Appl. 2015, 51, 3000-3011. [CrossRef] 
14. Grabowski, M.; Urbaniec, K.; Wernik, J.; Wołosz, K.J. Numerical simulation and experimental verification of heat transfer from a finned housing of an electric motor. Energy Convers. Manag. 2016, 125, 91-96. [CrossRef]

15. FLIR Systems, User's Manual I3,I5,I7, T559580; FLIR: Wilsonville, OR, USA, 2011.

16. Staton, D.A.; Cavagnino, A. Convection heat transfer and flow calculations suitable for electric machines thermal models. IEEE Trans. Ind. Electron. 2008, 55, 3509-3516. [CrossRef]

17. Pryor, R. Multiphysics Modeling Using COMSOL 5 and MATLAB; Mercury Learning \& Information: Dulles, VA, USA, 2016.

18. Oberkampf, W.L.; Trucano, T.G. Verification and validation benchmarks. Nucl. Eng. Des. 2008, 238, 716-743. [CrossRef]

19. Ho, S.L.; Fu, W.N. Analysis of indirect temperature-rise tests of induction machines using time stepping FEM. IEEE Trans. Energy Convers. 2001, 16, 55-60. [CrossRef]

2017 by the author. Licensee MDPI, Basel, Switzerland. This article is an open access article distributed under the terms and conditions of the Creative Commons Attribution (CC BY) license (http://creativecommons.org/licenses/by/4.0/). 